\title{
ON $\gamma$-QUASICONVEXITY, SUPERQUADRACITY AND TWO-SIDED REVERSED JENSEN TYPE INEQUALITIES
}

\author{
S. Abramovich, L.-E. Persson And N. SAmKo
}

\begin{abstract}
In this paper we deal with $\gamma$-quasiconvex functions when $-1 \leqslant \gamma \leqslant 0$, to derive some two-sided Jensen type inequalities. We also discuss some Jensen-Steffensen type inequalities for 1 -quasiconvex functions. We compare Jensen type inequalities for 1-quasiconvex functions with Jensen type inequalities for superquadratic functions and we extend the result obtained for $\gamma$-quasiconvex functions to more general classes of functions.
\end{abstract}

Mathematics subject classification (2010): 26D15.

Keywords and phrases: Refined Jensen type inequalities, superquadratic functions, convex functions, $\gamma$-quasiconvex functions.

\section{REFERENCES}

[1] S. Abramovich, S. Banić, M. Klaričić BakUla, A Variant of Jensen-Steffensen's Inequality for Convex and for Superquadratic Functions, J. Inequal. Pure Appl. Math. (JIPAM), 7 (2) Art 70, (2006).

[2] S. Abramovich, M. Klaričić Bakula, M. Matić, And J. PeČarić, A Variant of JensenSteffensen's Inequality and Quazi Arithmetic Means, J. Math. Anal. Appl., 307 (2005) 370-386.

[3] S. Abramovich, G. Jameson and G. Sinnamon, Refining Jensen's Inequality, Bull. Mathe. de la Soc. des Sciences Mathe de Roumanie, (Novel Series) 47 (95), (2004), 3-14.

[4] S. Abramovich And L. E. Persson, Some new refined Hardy type inequalities with breaking points $p=2$ or $p=3$, Proceedings of IWOTA 2011, Operator Theory: Advances and Applications, Vol. 236, 1-10, 2014, Birkhäuser, Springer-Basel.

[5] S. Abramovich And L. E. Persson, Some new scales of refined Hardy type inequalities via functions related to superquadracity, Math. Inequal. Appl. Vol. 16 (2013), 679-695.

[6] S. Abramovich, L. E. Persson And N. Samko, Some new scales of refined Jensen and Hardy type inequalities, Math. Inequal. Appl., Vol. 17 (2014), 1105-1114.

[7] J. A. Oguntuase And L. E. Persson, Refinement of Hardy's inequalities via superquadratic and subquadratic functions, J. Math. Anal. Appl. 339 (2008), 1305-1312.

[8] J. E. Pečarić, F. Proschan, Y. L. Tong, Convex Functions, Partial Orderings, and Statistical Applications, Academic Press, New York, 1992.

[9] L. E. PersSon AND N. SAMKo, Inequalities and convexity, Operator Theory: Advances and Applications, Birkhäuser Verlag, Basel, Vol. 1, (2013), 1-29.

[10] L. E. Persson, N. SAMKO AND P. WALL, Quasi-monotone weight functions and their characteristics and applications, Math. Inequal. Appl. 15 (2012), no. 3, 687-705. 